Original Article

\title{
Gross motor skill development of 5-year-old Kindergarten children in Myanmar
}

Thanda Aye, RPT, MS ${ }^{1,2)^{*}}$, Khin Saw Oo, MD, PhD ${ }^{3)}$, Myo Thuzar Khin, MD, PhD²), Tsugumi Kuramoto-Ahuja, RPT, MA ${ }^{1)}$, Hitoshi Maruyama, RPT, PhD ${ }^{1)}$

1) Department of Physical Therapy, Graduate School of Health and Welfare Sciences, International University of Health and Welfare: 2600-1 Kitakanemaru, Otawara city, Tochigi 324-8501, Japan

2) Department of Physiotherapy, University of Medical Technology, Yangon, Ministry of Health and Sports, Republic of the Union of Myanmar

3) Department of Physical Medicine and Rehabilitation, University of Medicine 2, Yangon, Ministry of Health and Sports, Republic of the Union of Myanmar

\begin{abstract}
Purpose] The purpose of this study was to examine the gross motor skill development of 5-year-old Kindergarten children in Myanmar. [Subjects and Methods] Total 472 healthy Kindergarten children (237 males, 235 females) of 2016-2017 academic year from four schools in urban area and four schools in rural area of Myanmar were recruited. The gross motor skill development of all subjects was assessed with the test of gross motor development second edition (TGMD-2). All subjects performed two trials for each gross motor skill and the performance was video recorded and scored. The assessment procedures were done according to the standardized guidelines of TGMD-2. [Results] The majority of subjects had average level of gross motor skill rank. The significant differences were found on the run and gallop of locomotor skills and the most of object control skills except the catch between males and females. The significant differences were also found between subjects from urban and rural areas. [Conclusion] Gross motor skill development of 5-year-old Kindergarten children in Myanmar had gender-based and region-based differences on both locomotor and object control skills. This study added a valuable information to the establishment of a normative reference of Kindergarten aged children for future studies.

Key words: Gross motor skill development, TGMD-2, Kindergarten children
\end{abstract}

(This article was submitted Jun. 4, 2017, and was accepted Jul. 7, 2017)

\section{INTRODUCTION}

The development of a child refers to the sequence of physical, language, thought and emotional changes that occur in a child from birth to the beginning of adulthood and it includes development of gross motor skills, fine motor skills, speech and language, cognition, social interaction, and emotional regulation ${ }^{1)}$. The development of gross motor skills in young children is important for further developmental functions such as perceptual and cognitive abilities ${ }^{2,3)}$. The government of the Republic of the Union of Myanmar has implemented a new National Education Strategic Plan (NESP) during the period 2016-2021 including a key reform focus on the provision of quality, healthy, play-centered pre-school, and primary education for all children aged 3 to 6 years ${ }^{4}$.

The quality kindergarten $(\mathrm{KG})$ program is one of the strategies of NESP and which has been implemented in all public schools, private schools, monastic schools and other types of schools across Myanmar by the Ministry of Education (MOE) since June 2016 ${ }^{5}$. The national education law of the Republic of the Union of Myanmar (2014) states that KG is education that promotes holistic development using appropriate methods for five year-olds to ease their transition to first grade and

*Corresponding author. Thanda Aye (E-mail: 15s3027@g.iuhw.ac.jp)

(C2017 The Society of Physical Therapy Science. Published by IPEC Inc.

(c) (1) $\odot$ This is an open-access article distributed under the terms of the Creative Commons Attribution Non-Commercial No Deriva-

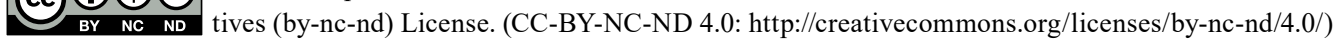


will be regarded as the base level of primary education ${ }^{6}$. The new KG curriculum, aligned with new primary curriculum supported by the government of Japan, supports the development of children in all developmental skills ${ }^{5,7}$.

Early assessment for the development of gross motor skills during preschool and elementary schools years is particularly important to monitor changes of motor development, identify delays or deficits of development, and assist Physical Therapists (PT) and other health care practitioners to properly design exercise programs ${ }^{8,9)}$.

Test of gross motor development second edition (TGMD-2) is one of the most widely used assessment tools to assess gross motor skill development of children ${ }^{3,10-13)}$. TGMD-2 is a standardized norm- and criterion-referenced test that measures gross motor abilities in children from 3-10 years of age ${ }^{9,11,12)}$. The test is used to identify children who are significantly behind their peers in gross motor skill development, plan an instructional program in gross motor skill development, assess individual progress in gross motor skill development, to evaluate the success of the gross motor program, and serve as a measurement instrument in research involving gross motor development. TGMD-2 is a highly reliable and valid assessment tool using normative sample of 1,208 persons residing in 10 states of the United States (US) and three sources of error variance, content sampling, time sampling, and inter-scorer differences, were analyzed in relation to TGMD-2 subtest and quotient scores ${ }^{9)}$.

Studies on gross motor skill development of children from preschools and elementary schools with TGMD-2 have been conducted in many countries ${ }^{14-38)}$. Most of the previous studies were conducted with typically developing children while some were conducted with children with special needs ${ }^{16,20,23,30,35)}$. Some of the existing studies reported assessment of gross motor skill development ${ }^{14-28)}$ but the others examined the efficacy of gross motor skill interventions ${ }^{29-38)}$. Some studies had found that no significant differences between the locomotor skills of males and females ${ }^{15,21,25)}$, while the others had found females to be superior ${ }^{17,18)}$. A number of studies had found that the object control skills were significantly better in males ${ }^{15,17-19,25,26)}$.

There is currently limited information on assessment of gross motor skill development of KG children in Myanmar and the development of gross motor skills in KG children is not known to be documented. Thus, the purpose of this study was to examine the gross motor skill development of 5-year-old KG children in Myanmar.

\section{SUBJECTS AND METHODS}

This study was a cross-sectional study and conducted with 472 healthy KG children ( 237 males, 235 females) who were attending for 2016-2017 academic year at four schools in urban area (three public and one private schools in Yangon city area) and four public schools in rural area (one township in Bago Region West, about $300 \mathrm{~km}$ to the North from Yangon) of Myanmar. The selection of the schools was decided by the township education officers from the MOE. The characteristics of the subjects were shown in Table 1 and 3. All the subjects from the private school were from high income families because they could afford to charge expensive school fees. The subjects from the public schools in this study were varied from high to low income families. Two public schools in urban area and two public schools in rural area were located in the wards and villages respectively of low income families.

The exclusion criteria were children with known developmental disability (e.g. Cerebral palsy, Down's syndrome, Autism Spectrum Disorder, Attention Deficit Hyperactive Disorder), obvious deformity (e.g. scoliosis, bow leg), and orthopedic injury in both upper and lower extremities within six months. Information on this study was provided to the principals, the teachers, the parents or guardians, and the children themselves before their voluntary participation. They were provided with written information letter and verbal explanation. The signed consent and oral assent were obtained from every parent or guardian and child for participation. This study was approved by the Ethics Review Committees (ERC) of International University of Health and Welfare, Japan (approval number: 15-Io-115) and the University of Medical Technology, Yangon, Myanmar (approval number: 3/2016) and endorsed by the ERC of the department of Medical Research, Ministry of Health and Sports (MOHS), Myanmar. The official approval letter for the schools was obtained from the MOE, Myanmar.

The main equipment used was TGMD-2, which reliability was tested before and other materials used were a stadiometer and weighing scale (KENXIN, Health scale, BWS-302), two 8- to 10-inch playground balls, one basketball, one soccer ball, one 4-inch light weight ball, one tennis ball, one softball, one 4- to 5 inch square beanbag, color tapes, two traffic cones, one plastic bat, one batting tee, and a video camera (Sony HD, HDR-PJ410). TGMD-2 consists of 12 gross motor skills divided into locomotor and object control subtests. Locomotor subtest includes run, gallop, hop, leap, horizontal jump, and slide. There are four performance criteria for each skill of run, gallop, horizontal jump, and slide, while hop has five and leap has three criteria, and total 24 criteria for locomotor subtest. Object Control subtest includes striking a stationary ball, stationary dribble, catch, kick, overhand throw, and underhand roll. There are five performance criteria for striking a stationary ball, three for catch, while all the rest four items have four for each, and also total 24 for object control subtest. Each skill is performed two trials for assessment and each criterion is given a score of 1 or 0 for the pass and fail attempt respectively. The scores of two trials are added up to get total criterion score, the total criterion scores for the performance criteria are added up to get skill score, the six-skill scores are added up to get subtest raw scores ( $0-48)$. The subtest raw scores are converted into standard scores (1-20) and percentiles $(<1->99)$ depending on age and gender according to the normed tables in TGMD-2 manual. The standard scores of locomotor and object control subtests are added up and converted into gross motor quotient (GMQ) (46-160). Finally, seven descriptive ratings: very poor, poor, below average, average, above average, superior, and 
Table 1. Comparison between male and female subjects

\begin{tabular}{lcccc}
\hline & Male & Female & $\mathrm{p}$ & Total \\
\hline Number (\%) & $237(50.2)$ & $235(49.8)$ & & $472(100)$ \\
Age (years) & $5.43 \pm 0.35$ & $5.39 \pm 0.33$ & & $5.41 \pm 0.34$ \\
Height (cm) & $105.5 \pm 7.16$ & $106.3 \pm 7.16$ & & $105.9 \pm 7.17$ \\
Weight $(\mathrm{kg})$ & $17.3 \pm 3.11$ & $17.3 \pm 2.87$ & & $17.3 \pm 2.99$ \\
BMI $\left(\mathrm{kg} / \mathrm{m}^{2}\right)$ & $15.6 \pm 2.02$ & $15.3 \pm 1.82$ & & $15.4 \pm 1.93$ \\
Run & $7.08 \pm 1.54$ & $6.66 \pm 1.89$ & $*$ & $6.87 \pm 1.74$ \\
Gallop & $6.52 \pm 2.34$ & $7.15 \pm 1.86$ & $* *$ & $6.83 \pm 2.13$ \\
Hop & $8.81 \pm 2.20$ & $8.63 \pm 2.55$ & & $8.72 \pm 2.38$ \\
Leap & $4.00 \pm 1.82$ & $3.88 \pm 1.63$ & & $3.94 \pm 1.73$ \\
Horizontal jump & $5.18 \pm 2.28$ & $5.12 \pm 1.96$ & & $5.15 \pm 2.13$ \\
Slide & $7.18 \pm 1.84$ & $7.18 \pm 1.57$ & & $7.18 \pm 1.72$ \\
Locomotor raw scores & $38.8 \pm 7.66$ & $38.6 \pm 7.07$ & & $38.7 \pm 7.36$ \\
Locomotor standard scores & $12.9 \pm 3.74$ & $12.6 \pm 3.48$ & & $12.8 \pm 3.61$ \\
Locomotor percentiles & $71.7 \pm 29.0$ & $71.3 \pm 27.4$ & & $71.5 \pm 28.2$ \\
Striking a stationary ball & $7.53 \pm 2.18$ & $6.59 \pm 2.22$ & $* * *$ & $7.06 \pm 2.25$ \\
Stationary dribble & $2.37 \pm 3.15$ & $1.79 \pm 2.81$ & $*$ & $2.08 \pm 2.99$ \\
Catch & $3.58 \pm 1.77$ & $3.39 \pm 1.81$ & & $3.49 \pm 1.79$ \\
Kick & $7.47 \pm 1.27$ & $6.79 \pm 1.79$ & $* * *$ & $7.13 \pm 1.59$ \\
Overhand throw & $5.68 \pm 2.23$ & $4.73 \pm 2.41$ & $* * *$ & $5.21 \pm 2.37$ \\
Underhand roll & $5.16 \pm 1.98$ & $4.56 \pm 1.52$ & $* * *$ & $4.86 \pm 1.79$ \\
Object control raw scores & $31.8 \pm 7.53$ & $27.8 \pm 7.30$ & $* * *$ & $29.8 \pm 7.67$ \\
Object control standard scores & $10.0 \pm 2.65$ & $10.2 \pm 2.95$ & & $10.1 \pm 2.81$ \\
Object control percentiles & $49.2 \pm 26.9$ & $50.5 \pm 29.1$ & & $49.8 \pm 28.0$ \\
Sum of standard scores & $22.9 \pm 5.02$ & $22.8 \pm 5.27$ & & $22.9 \pm 5.14$ \\
Gross motor quotient & $108.3 \pm 16.3$ & $108.4 \pm 15.8$ & & $108.3 \pm 16.0$ \\
\hline
\end{tabular}

Mean \pm SD

p: Significant difference between male and female, ${ }^{*} \mathrm{p}<0.05,{ }^{* *} \mathrm{p}<0.01,{ }^{* * *} \mathrm{p}<0.001$

very superior are given for the subtest standard scores and the GMQ for evaluation ${ }^{9}$.

The height and weight of every child was measured with the stadiometer and weighing scale and the BMI was calculated before assessing the development of gross motor skills. The test venue and equipment were set up according to TGMD-2 requirements in the indoor assembly halls or the outdoor playground of the public schools and the indoor gymnasium of the private school. The researchers thoroughly explained and demonstrated correct performance of all 12 gross motor skills of TGMD-2 before the assessment. After that, each child started to perform each gross motor skill under supervision of the researchers and the KG class teachers. The child was allowed at least one test trial for each gross motor skill. The child had to perform two trials for each of all 12 gross motor skills (rest period was provided between two consecutive gross motor skill tests). The performance of every child was video-recorded. The video camera was fixed in the proper position and angle to record the whole performance of each motor skill, except recording of run, gallop and slide when the angle of the video camera was changed to record the whole performance. Total duration of assessment of all 12 gross motor skills for each child lasted about 10-15 minutes (including rest periods). The subjects were assessed with their barefooted performance of all skills because the majority of the subjects were not accustomed to wear rubber-soled shoes. The assessment procedures were done according to the standardized guidelines of TGMD-2 and finished within three consecutive months for all 472 children. The video recordings were assessed and rated with TGMD-2 examiner's record forms by three raters (inter-rater reliability determined by the intra-class correlation coefficients from $0.88-0.95$ ).

The descriptive statistics and one-way ANOVA was used to analyze the data. The significant level was set as $p<0.05$. The software used for data analysis was IBM SPSS statistic version 22.0 for Windows.

\section{RESULTS}

Table 1 shows the results of one-way ANOVA between male and female subjects. The significant differences were found on the run and gallop but there were no significant differences on the rest of locomotor skills between males and females. The significant differences were also found on the most of object control skills except the catch, object control standard and 
Table 2. Descriptive rating of Gross Motor Quotient

\begin{tabular}{lcc}
\hline Descriptive Rating of GMQ & Frequency & Percent \\
\hline Average & 218 & 46.2 \\
Above average & 95 & 20.1 \\
Below average & 29 & 6.1 \\
Poor & 12 & 2.5 \\
Superior & 83 & 17.6 \\
Very poor & 3 & 0.6 \\
Very superior & 32 & 6.8 \\
Total & 472 & 100.0 \\
\hline
\end{tabular}

GMQ: Gross motor quotient

Table 3. Comparison of subjects between urban and rural areas

\begin{tabular}{lcccc}
\hline & Urban Schools & Rural Schools & p & Total \\
\hline Number $(\%)$ & $357(75.6)$ & $115(24.4)$ & & $472(100)$ \\
Age $($ years $)$ & $5.36 \pm 0.31$ & $5.56 \pm 0.39$ & $* * *$ & $5.41 \pm 0.34$ \\
Height $(\mathrm{cm})$ & $107.2 \pm 7.18$ & $102.0 \pm 5.57$ & $* * *$ & $105.9 \pm 7.17$ \\
Weight $(\mathrm{kg})$ & $17.6 \pm 3.10$ & $16.3 \pm 2.36$ & $* * *$ & $17.3 \pm 2.99$ \\
BMI $\left(\mathrm{kg} / \mathrm{m}^{2}\right)$ & $15.3 \pm 2.02$ & $15.7 \pm 1.56$ & & $15.4 \pm 1.93$ \\
Run & $6.59 \pm 1.85$ & $7.76 \pm 0.84$ & $* * *$ & $6.87 \pm 1.74$ \\
Gallop & $6.70 \pm 2.23$ & $7.23 \pm 1.75$ & $*$ & $6.83 \pm 2.13$ \\
Hop & $8.57 \pm 2.46$ & $9.18 \pm 2.05$ & $*$ & $8.72 \pm 2.38$ \\
Leap & $3.62 \pm 1.79$ & $4.92 \pm 1.00$ & $* * *$ & $3.94 \pm 1.73$ \\
Horizontal jump & $5.01 \pm 2.12$ & $5.59 \pm 2.08$ & $* *$ & $5.14 \pm 2.13$ \\
Slide & $7.01 \pm 1.77$ & $7.49 \pm 1.49$ & $*$ & $7.18 \pm 1.72$ \\
Locomotor raw scores & $37.6 \pm 7.35$ & $42.1 \pm 6.25$ & $* * *$ & $38.7 \pm 7.36$ \\
Locomotor standard scores & $12.2 \pm 3.46$ & $14.6 \pm 3.43$ & $* * *$ & $12.8 \pm 3.61$ \\
Locomotor percentiles & $67.5 \pm 28.4$ & $84.1 \pm 23.5$ & $* * *$ & $71.5 \pm 28.2$ \\
Striking a stationary ball & $7.29 \pm 2.22$ & $6.36 \pm 2.19$ & $* * *$ & $7.06 \pm 2.25$ \\
Stationary dribble & $2.33 \pm 3.08$ & $1.30 \pm 2.56$ & $* * *$ & $2.08 \pm 2.99$ \\
Catch & $3.46 \pm 1.75$ & $3.56 \pm 1.90$ & & $3.48 \pm 1.79$ \\
Kick & $7.09 \pm 1.60$ & $7.23 \pm 1.56$ & & $7.13 \pm 1.59$ \\
Overhand throw & $4.99 \pm 2.47$ & $5.86 \pm 1.89$ & $* * *$ & $5.21 \pm 2.37$ \\
Underhand roll & $4.99 \pm 1.90$ & $4.47 \pm 1.31$ & $* *$ & $4.86 \pm 1.79$ \\
Object control raw scores & $30.1 \pm 7.81$ & $28.8 \pm 7.12$ & & $29.8 \pm 7.67$ \\
Object control standard scores & $10.3 \pm 2.84$ & $9.51 \pm 2.61$ & $* *$ & $10.1 \pm 2.81$ \\
Object control percentiles & $51.8 \pm 28.2$ & $43.6 \pm 26.8$ & $* *$ & $49.8 \pm 28.0$ \\
Sum of standard scores & $22.4 \pm 5.29$ & $24.1 \pm 4.43$ & $* *$ & $22.9 \pm 5.14$ \\
Gross motor quotient & $107.0 \pm 16.6$ & $112.4 \pm 13.3$ & $* *$ & $108.3 \pm 16.0$ \\
\hline Mean \pm SD Signifi*
\end{tabular}

Mean \pm SD, p: Significant differences between urban and rural schools, ${ }^{*} \mathrm{p}<0.05,{ }^{* *} \mathrm{p}<0.01,{ }^{* * *} \mathrm{p}<0.001$

percentile scores between two genders.

Seven levels of descriptive rating according to the GMQ for all the subjects are shown in Table 2. The majority of subjects $(46.2 \%, n=218)$ had average level of gross motor skill rank. The minority $(0.6 \%, n=3)$ had very poor level of gross motor skill rank.

Table 3 shows the comparison of the subjects between urban and rural areas. The significant differences were found between the two groups. 


\section{DISCUSSION}

The findings of this study showed that the gross motor skill development of KG children in Myanmar had a different tendency across gender and geographical region. The majority of the subjects demonstrated average level of overall skill rank.

The mean standard score for locomotor subtest was better than the US normative samples while the mean standard score for object control subtest was matched with the US normative samples. The standard scores for both locomotor and object control subtests had a mean of 10 and standard deviation of 3 for the US normative samples ${ }^{9}$. This finding was in line with the study of Pang and Fong in which Hong Kong Chinese children performed better than the US normative samples ${ }^{14)}$.

The males performed significantly better in the run than the females, while the females did in the gallop than the males. There were no significant differences on all the rest of locomotor skills between the males and females. The findings of this study were similar to the previous studies. Goodway et al. reported that no significant differences were found between males and females for locomotor skills in the preschoolers from two geographical regions in the US ${ }^{15)}$. Bakhtiar also stated the similar findings for 6-year-old children in Indonesia ${ }^{21}$. It was found that males and females aged between six and nine in Taiwan had roughly equal locomotor skills in the study of Lin and Yang ${ }^{25)}$. The gender-based differences on locomotor skills of this study were differed from Hardy et al. in which the females subjects of preschool children in Australia tended to have higher mastery of locomotor skills ${ }^{17)}$. Legear et al. also reported that the females had superior locomotor proficiency in KG children in Canada ${ }^{18}$.

In this study, the males performed significantly better in five out of six individual object control skills and total raw skill. The findings were concurred with the previous studies. There were significant differences on object control skills in the males among preschoolers from the US in the study of Goodway et $\mathrm{al}^{15}$. The findings of this study agreed with Hardy et al. in which the males had higher total and individual object control skills except the catch ${ }^{17}$. The better object control skills among males had also found in the study of Legear et al. ${ }^{18)}$. Bardid et al. reported that the males had better performance on object control skills in Belgian children ${ }^{19}$. Bakhtiar had found that the males were slightly higher in object control skills than the females ${ }^{21)}$. Lin and Yang had also reported that the significant differences were found in object control skills except the catch and the kick between the two genders ${ }^{25)}$.

The number of subjects from urban and rural area were significantly different because of demography of the population in those two study areas. The population who live in urban area is the highest (70.1\%) in Yangon ${ }^{39)}$. In this study, $75.6 \%$ of the subjects were from urban area. This result was similar to the original TGMD-2 manual where $77 \%$ of the US normative samples were from urban area ${ }^{9}$.

The significant differences on most of the gross motor skills except the catch, the kick and the raw object control scores were found between urban and rural areas. All locomotor skills of the subjects from rural area were significantly better than those from urban area. This differences may be due to plenty of open spaces for play around schools and home environments in rural area. Another possible reason may be due to the circumstance in rural area where most of children used to walk to schools because of lack of accessible public transportation to schools.

Conversely, the subjects from urban area had better performances on most of object control skills. This may be due to the subjects from one private schools in this study where well facilitated indoor gymnasium and outdoor playground are situated.

The findings from this study have implications for PTs, physical education teachers, and other professionals who are working for early childhood care and development programs.

The strength of this study was that it was conducted with a large sample of KG children attending at the public and private schools in Myanmar. The first limitation of this study was the subjects were only from two regions out of total 15 regions (seven regions, seven states and one union territory) of Myanmar. The second limitation was the schools were selected based on the different geographical regions and this study could not differentiate the two areas based on socioeconomic status (SES). The objective assessment of SES of the families of all the subjects should have been done for accurate differentiation between two study areas. The third limitation was the subjects were not assessed their nutrition, culture, and ethnicity, although the majority of residents in the two study areas were Bamar which was one out of eight major national ethnic races of Myanmar. Further studies are still needed to examine KG children from all the 15 regions of Myanmar and whether the differences of the gross motor skill development depending on the families' SES and the nutrition, culture, and ethnicity of children.

In conclusion, the development of gross motor skills in KG children in Myanmar had gender-based and region-based differences on both the locomotor and object control skills. The findings of this study gave a valuable information to the establishment of a normative reference of $\mathrm{KG}$ aged children for future studies.

\section{Conflict of interest}

No conflict of interest was declared. 


\section{REFERENCES}

1) Kid Sense Child Development Corporation Pty Ltd @ 2017 https://childdevelopment.com.au/areas-of-concern/what-is-child-development/ (Accessed May 9, 2017)

2) Piek JP, Dawson L, Smith LM, et al.: The role of early fine and gross motor development on later motor and cognitive ability. Hum Mov Sci, 2008, 27: 668-681. [Medline] [CrossRef]

3) Veldman SL, Jones RA, Okely AD: Efficacy of gross motor skill interventions in young children: an updated systematic review. BMJ Open Sport Exerc Med, 2016, 2: e000067. [Medline] [CrossRef]

4) Aung San Suu Kyi: Foreword. In: National education strategic plan 2016-21. The government of the Republic of the Union of Myanmar, Ministry of Education, 2016, p 5. http://www.moe.gov.mm (Accessed Apr. 10, 2017)

5) National education strategic plan 2016-21. The government of the Republic of the Union of Myanmar, Ministry of Education, 2016, pp 70-83. http://www.moe. gov.mm (Accessed Apr. 10, 2017)

6) National Education Law: Myanmar, 2014 (41/2014). http://www.ilo.org/dyn/natlex/natlex4.detail?p_lang=en\&p_isn=100493\&p_count=3\&p_classification=09 (Accessed Apr. 10, 2017)

7) Meyer C: Bilingual support for the new Kindergarten Curriculum in Myanmar. 5th International conference on language and education, 19-21 October 2016, Bangkok, Thailand http://www.lc.mahidol.ac.th/mleconf/2016/Documents/PresentedFiles/Parallel\%20V/T3-4/64C-Cliff-Meyers.pdf (Accessed May 11, 2017)

8) Valentini NC: Validity and reliability of the TGMD-2 for Brazilian children. J Mot Behav, 2012, 44: 275-280. [Medline] [CrossRef]

9) Ulrich DA: Test of gross motor development: examiner's manual, 2nd ed. Austin: Pro-Ed publisher, 2000, pp 1-60.

10) De Mediros P, Zequinao MA, Fronza FC, et al.: Motor assessment instruments and psychometric procedures: a systematic review. Motricidade, 2016, 12: 64-75 http://revistas.rcaap.pt/motricidade/article/view/6397 (Accessed Jun. 20, 2017)

11) Human Kinetics. Test Instruments Used in Adapted Physical Education. http://www.humankinetics.com/excerpts/excerpts/test-instruments-used-in-adaptedphysical-education (Accessed Jul. 3, 2017)

12) Connolly BH: Examination and evaluation: Tests and administration. In: Therapeutic exercises in developmental disabilities, 3rd ed. SLACK Incorporated, 2005, pp 21-79.

13) Cools W, Martelaer KD, Samaey C, et al.: Movement skill assessment of typically developing preschool children: a review of seven movement skill assessment tools. J Sports Sci Med, 2009, 8: 154-168. [Medline]

14) Pang AW, Fong DT: Fundamental motor skill proficiency of Hong Kong children aged 6-9 years. Res Sports Med, 2009, 17: 125-144. [Medline] [CrossRef]

15) Goodway JD, Robinson LE, Crowe H: Gender differences in fundamental motor skill development in disadvantaged preschoolers from two geographical regions. Res Q Exerc Sport, 2010, 81: 17-24. [Medline] [CrossRef]

16) Staples KL, Reid G: Fundamental movement skills and autism spectrum disorders. J Autism Dev Disord, 2010, 40: 209-217. [Medline] [CrossRef]

17) Hardy LL, King L, Farrell L, et al.: Fundamental movement skills among Australian preschool children. J Sci Med Sport, 2010, 13: 503-508. [Medline] [CrossRef]

18) LeGear M, Greyling L, Sloan E, et al.: A window of opportunity? Motor skills and perceptions of competence of children in kindergarten. Int J Behav Nutr Phys Act, 2012, 9: 29 http://www.ijbnpa.org/content/9/1/29 (Accessed Apr. 12, 2017) [Medline] [CrossRef]

19) Bardid F, Huyben F, Lenoir M, et al.: Assessing fundamental motor skills in Belgian children aged 3-8 years highlights differences to US reference sample. Acta Paediatr, 2016, 105: e281-e290. [Medline] [CrossRef]

20) Nonis KP, Jernice TS: The gross motor skills of children with mild learning disabilities. Int J Spec Educ, 2014, 29: 92-97.

21) Bakhtiar S: Fundamental motor skill among 6-year-old children in Padang, West Sumatera, Indonesia. Asian Soc Sci, 2014, 10: 155-158 http://www.ccsenet. org/journal/index.php/ass/article/viewFile/34763/19866 (Accessed Jun. 21, 2016) [CrossRef]

22) Hashim A, Baharom M: Research level of gross motor development and age equivalents of children 7 to 9 years. Int J Educ Learn Dev, 2014, 2: $48-59$ http:// www.eajournals.org/wp-content/uploads/Research-Level-of-Gross-Motor-Development-and-Age-Equivalents-of-Children-7-To-9-Years.pdf (Accessed Dec. 15, 2016)

23) Zawi k, Lian DKC, Abdullah RT: Gross motor development of Malaysian hearing impaired male pre- and early school children. Int Educ Stud, 2014, 7: 242-252 http://files.eric.ed.gov/fulltext/EJ1071165.pdf (Accessed Dec. 15, 2016)

24) Barnett LM, Ridgers ND, Salmon J: Associations between young children's perceived and actual ball skill competence and physical activity. J Sci Med Sport, 2015, 18: 167-171. [Medline] [CrossRef]

25) Lin SJ, Yang SC: Development of fundamental movement skills by children aged six to nine. Universal Journal of Educational Research, 2015, 3(12), 10241027. http://www.hrpub.org/journals/article_info.php?aid=3116 (Accessed Dec.15, 2016)

26) Yang SC, Lin SJ, Tsai CY: Effect of sex, age, and BMI on the development of locomotor skills and object control skills among preschool children. Percept Mot Skills, 2015, 121: 873-888. [Medline] [CrossRef]

27) Barnett LM, Salmon J, Hesketh KD: More active pre-school children have better motor competence at school starting age: an observational cohort study. BMC Public Health, 2016, 16: 1068. [Medline] [CrossRef]

28) Draper CE, Tomaz SA, Stone M, et al.: Developing intervention strategies to optimize body composition in early childhood in South Africa. BioMed Res Int, 2017, 2017: 5283457 [CrossRef]. [Medline]

29) Robinson LE, Goodway JD: Instructional climates in preschool children who are at-risk. Part I: object-control skill development. Res Q Exerc Sport, 2009, 80: 533-542. [Medline]

30) Breslin CM, Rudisill ME: The effect of visual supports on performance of the TGMD-2 for children with autism spectrum disorder. Adapt Phys Activ Q, 2011, 28: 342-353. [Medline] [CrossRef]

31) Jones RA, Riethmuller A, Hesketh K, et al.: Promoting fundamental movement skill development and physical activity in early childhood settings: a cluster randomized controlled trial. Pediatr Exerc Sci, 2011, 23: 600-615. [Medline] [CrossRef] 
32) Lemos AG, Avigo EL, Barela JA: Physical education in kindergarten promotes fundamental motor skill development. Advances in Physical Education/ Sci Res, 2012, 2: 17-21. http://file.scirp.org/pdf/APE20120100002_17001440.pdf (Accessed May. 7, 2017).

33) Alhassan S, Nwaokelemeh O, Ghazarian M, et al.: Effects of locomotor skill program on minority preschoolers' physical activity levels. Pediatr Exerc Sci, 2012, 24: 435-449. [Medline] [CrossRef]

34) Kordi R, Nourian R, Ghayour M, et al.: Development and evaluation of a basic physical and sports activity program for preschool children in nursery schools in Iran: an interventional study. Iran J Pediatr, 2012, 22: 357-363. [Medline]

35) Gursel F: Inclusive intervention to enhance the fundamental movement skills of children without hearing: a preliminary study. Percept Mot Skills, 2014, 118: 304-315. [Medline] [CrossRef]

36) Tsapakidou A, Stefanidou S, Tsompanaki E: Locomotor development of children aged 3.5 to 5 years in nursery schools in Greece. Rev Eur Stud, 2014, 6: 1-6. [CrossRef]

37) Donath L, Faude O, Hagmann S, et al.: Fundamental movement skills in preschoolers: a randomized controlled trial targeting object control proficiency. Child Care Health Dev, 2015, 41: 1179-1187. [Medline] [CrossRef]

38) Adamo KB, Wilson S, Harvey AL, et al.: Does intervening in childcare settings impact fundamental movement skill development? Med Sci Sports Exerc, 2016, 48: 926-932. [Medline] [CrossRef]

39) Provisional results. In. Population and housing census of Myanmar, 2014. The government of the Republic of the Union of Myanmar, Ministry of Immigration and population, 2014,pp 6-36.http://www.themimu.info/sites/themimu.info/files/documents/Ref_Doc_Census_Provisional_Results_2014.pdf(Accessed May 18, 2017) 